\title{
Kinetics and Mechanism of the Oxidation of Coomassie Brilliant Blue-R Dye by Hypochlorite and Role of Acid Therein
}

\author{
Srinivasu Nadupalli, Venkata D.B.C. Dasireddy, Neil A. Koorbanally and \\ Sreekantha B. Jonnalagadda* \\ School of Chemistry and Physics, University of KwaZulu-Natal, Westville Campus, Private Bag X54001, Durban 4000, South Africa.
}

Received 18 July 2014, revised 18 February 2015, accepted 8 April 2015.

\begin{abstract}
The kinetics of the oxidation of a triphenylmethane dye, Brilliant Blue- $\mathrm{R}\left(\mathrm{BB}^{-} \mathrm{Na}^{+}\right)$, in aqueous solution by hypochlorite as a function of $\mathrm{pH}$ was investigated. While the degradation of dye obeyed pseudo-first-order kinetics, the oxidation of the dye occurred through two competitive reactions facilitated by $\left[\mathrm{OCl}^{-}\right]$and $[\mathrm{HOCl}]$. Both reactions exhibited first-order dependence on $\left[\mathrm{OCl}^{-}\right]$ and $[\mathrm{HOCl}]$, respectively, but the hypochlorous acid initiated reaction was about ten times faster. The relative importance of the two paths rested on the $\mathrm{pH}$-dependent concentrations of hypochlorite and hypochlorous acid. The overall second-order rate constants for the $\mathrm{OCl}^{-}$and $\mathrm{HOCl}$ initiated reactions are $1.2 \pm 0.2 \mathrm{M}^{-1} \mathrm{~s}^{-1}$ and $22.2 \pm 1.2 \mathrm{M}^{-1} \mathrm{~s}^{-1}$, respectively. The reaction energy param-

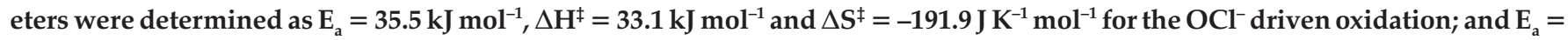
$26.8 \mathrm{~kJ} \mathrm{~mol}^{-1}, \Delta \mathrm{H}^{\ddagger}=29.3 \mathrm{~kJ} \mathrm{~mol}^{-1}$ and $\Delta \mathrm{S}^{\ddagger}=-204.6 \mathrm{~J} \mathrm{~K}^{-1} \mathrm{~mol}^{-1}$ for the $\mathrm{HOCl}$ facilitated reaction. The governing rate law and probable reaction mechanism were elucidated and validated by simulation. The three main oxidation products were 4-(4-ethoxyphenylamino)benzoic acid, 3-[(ethyl-hydroxyamino)methyl]benzene sulfonic acid and 6'-chloro-5'-hydroxybicyclohexylidene-2,5,2' -triene-4, $4^{\prime}$-dione.
\end{abstract}

KEYWORDS

Brilliant Blue-R, oxidative degradation, hypochlorite, hypochlorous acid, kinetics, simulations.

\section{Introduction}

The effective treatment of effluent arising from the textile industry is a complex problem as these wastewaters are highly coloured and polluted. ${ }^{1}$ In this communication we focus on the degradation of Brilliant Blue- $\mathrm{R}\left(\mathrm{BB}^{-} \mathrm{Na}^{+}\right)$, a triphenylmethane dye. ${ }^{2}$ It is also known by other names such as Acid Blue 83 , Acid Brilliant Blue and Brilliant Indocyanine 6B. It was originally developed for dyeing wool, silk and nylon in the textile indus try. ${ }^{2}$ It is also used extensively in the paint, ink, plastic and leather industries. This dye is water-soluble and readily dissociates into $\mathrm{BB}^{-}$and $\mathrm{Na}^{+}$. The aqueous dye exhibits two main peaks in its UV-visible absorption spectrum, one at $285 \mathrm{~nm}$ and the other at $555 \mathrm{~nm}\left(\varepsilon=4.3 \times 10^{4} \mathrm{~cm}^{-1} \mathrm{M}^{-1}\right)$ that show no shift due to pH change. ${ }^{3}$

Hypochlorite is extensively used as a broad-spectrum antimicrobial agent, as a household bleach, as a chlorinating agent (for swimming pools and in wastewater treatment) and also in endodontic procedures. ${ }^{4-9}$ We have previously reported the effect of hypochlorite enriched seawater for the treatment of wastewater. ${ }^{10}$ We have also reported the oxidation kinetics and mechanisms of reactions of triary $1^{11,12}$ (aniline blue and thymol blue), phenothiazine $^{13}$ (methylene blue) and heterocyclic ${ }^{14,15}$ (acridine orange and safranine-o) dyes with acidic bromate as oxidant. We also investigated the oxidative degradation kinetics of indigo carmine with hypochlorite ${ }^{16}$ and the reaction kinetics of triaryl ${ }^{17}$ (methylene violet), benzophenoxazines ${ }^{18}$ (Nile blue and Meldola's blue) and phenothiazine ${ }^{19}$ (toluidine blue) dyes with chlorite under low pH conditions. More recently, we investigated and reported the kinetics and mechanism of oxidation of

* To whom correspondence should be addressed. E-mail: jonnalagaddas @ ukzn.ac.za the toxic dye, amaranth, by hypochlorite and hypochlorous acid under varied $\mathrm{pH}$ conditions..$^{20,21}$

In this communication we present and describe the details of the kinetics and the reaction mechanisms of decolourization of $\mathrm{BB}^{-}$by hypochlorite in aqueous solutions as a function of $\mathrm{pH}$. The oxidation products after decolorization of the dye were isolated and characterized immediately.

\section{Experimental}

\subsection{Reagents}

All chemicals were of Analar grade and all the solutions were prepared in double-distilled water. Coomassie Brilliant Blue-R $(\mathrm{FW}=825)($ Aldrich), sodium hydroxide $(\mathrm{BDH}), 98 \%$ sulfuric acid (BDH) and anhydrous sodium sulfate (Univar) were used as supplied. The hypochlorite solutions were prepared as per the procedure described by Nagypal et al., ${ }^{22}$ and were standardized by iodometric titration. Standardized solutions of sulfuric acid $(0.1 \mathrm{M})$ or sodium hydroxide $(0.1 \mathrm{M})$ were used to adjust the $\mathrm{pH}$ and sodium sulfate was used to maintain the ionic strength.

\subsection{Kinetic Measurements}

The kinetic measurements of the reaction between hypochlorite and Brilliant Blue-R $\left(\mathrm{BB}^{-}\right)$were conducted on a Hi-Tech stopped-flow spectrophotometer (Hi-Tech SF-61 DX2 doublemixing micro-volume stopped-flow, Salisbury, UK). The spectrophotometer was interfaced with a computer to collect data as changes in signal volt or absorbance versus time. The reaction was monitored at $555 \mathrm{~nm}$. Unless otherwise stated, all 
the experiments were carried out at $25.0 \pm 0.1^{\circ} \mathrm{C}$. The kinetics data was analyzed by means of the KinetAsyst ${ }^{\mathrm{TM}} 3.10$ software. This involved fitting the data to a suitable model. A HACH EC40 pH/ISE meter, with digital data output, was used to record the $\mathrm{pH} /$ potential changes.

\subsection{Product Characterization}

A mixture of Brilliant Blue-R (500 mg) and a 100-fold molar excess of oxidant with the requisite excess amount of sulfuric acid was continuously stirred with a magnetic stirrer at room temperature. Immediately after decolourization of the dye, the reaction products from the aqueous reaction mixtures were extracted with diethyl ether $(3 \times 200 \mathrm{~mL})$. The solvent was dried over anhydrous calcium carbonate and evaporated to dryness. The crude extract was purified by column chromatography on a column (4 cm diameter) containing silica gel (Merck 9385) as the stationary phase and with a hexane:dichloromethane mixture $(85: 15 \mathrm{v} / \mathrm{v})$ as the eluent. The isolated products were characterized by GC-MS and NMR $\left({ }^{1} \mathrm{H}\right.$ and $\left.{ }^{13} \mathrm{C}\right)$, where possible.

\section{Results and Discussion}

\subsection{Product Analysis and Stoichiometry}

The crude reaction mixture was extracted with diethyl ether and the products were separated by column chromatography. Only three compounds were observed by TLC, $\mathrm{P}_{1}, \mathrm{P}_{2}$ and $\mathrm{P}_{3}$. The separated products were identified by ${ }^{1} \mathrm{H}$ - and ${ }^{13} \mathrm{C}-\mathrm{NMR}$. Scheme 1 illustrates the products obtained.

To the best of our knowledge, $\mathrm{P}_{1}$ is a commercially available compound and $\mathrm{P}_{2} / \mathrm{P}_{3}$ and $\mathrm{P}_{4}$ have not been reported in the literature. The ${ }^{1} \mathrm{H}$ NMR spectrum of product $\mathrm{P}_{1}$ (Online supplement, Fig. S1) showed the presence of a pair of doublets at $\delta 8.00$ and $\delta 7.49$, attributed to the para-substituted rings of $P_{1}$. The fact that there is only one pair of doublets indicates that the orthocoupled protons on one of the rings are equivalent to that of the other, presumably due to similar groups being present on both of the aromatic rings. The ethoxy group is also indicated by the deshielded quartet resonance at $\delta 4.11$ and the triplet methyl resonance at $\delta 1.21$. The ${ }^{13} \mathrm{C}$ NMR spectrum (Online supplement, Fig. S2) showed the presence of aromatic carbon resonances at $\delta 110-140$ with the carbonyl resonance present at $\delta_{\mathrm{C}} 173.04$ and the aromatic $\mathrm{C}-\mathrm{O}$ resonance present at $\delta_{\mathrm{C}} 168.75$. The deshielded methylene resonance of the ethoxy group can be seen at $\delta_{C} 61.56$ and the methyl carbon resonance can be seen at $\delta_{\mathrm{C}} 14.47$. The molecular ion can be seen at $\mathrm{m} / \mathrm{z} 257$ (Online supplement, Fig. S3).

The proton NMR spectrum of the identified product $P_{2}$ revealed that appearance of a triplet and quartet for the methyl and methylene group at $\delta 0.92$ and $\delta 2.29$, respectively. The protons of the methylene group, which serves as bridge between phenyl ring and tertiary nitrogen, is seen at a higher chemical shift, $\delta 3.81$. All aromatic protons are seen between $\delta 7.0$ and 7.65 (Online supplement, Fig. S4). The ${ }^{13} \mathrm{C}$ NMR spectrum exhibited the appearance of methyl and methylene carbons at $\delta 13.71$ and $\delta 37.37$, respectively. The downfield resonance of $\delta 64.7$ for the methylene carbon is observed due to the deshielding effect between the phenyl and tertiary nitrogen. Aromatic carbons are observed between $\delta 130.96$ and 144.63 (Online supplement, Fig. S4).

The ${ }^{1} \mathrm{H}$ NMR spectrum of product $\mathrm{P}_{3}$ (Online supplement, Fig. S7) showed two pairs of doublets with the integration of two of the doublets being twice that of the other two. This indicated that one of the quinine rings was un-substituted with proton resonances at $\delta_{\mathrm{H}} 7.39$ and 8.12 and that in the other ring, addition has taken place across one of the double bonds, resulting in only one double bond with resonances at $\delta_{\mathrm{H}} 6.42$ and 7.80. The ${ }^{13} \mathrm{C}$ NMR spectrum (Online supplement, Fig. S8) exhibited carbonyl resonances of the bicyclic quinine at $\delta_{\mathrm{C}} 168.91$ and $\delta \mathrm{C}$ 172.27. The other quinone resonances can be seen between $\delta_{\mathrm{C}}$ 168.91 and $\delta_{\mathrm{C}} 140.51$. The molecular ion can be seen at $\mathrm{m} / \mathrm{z} 251$ $\left(\mathrm{M}^{+}\right)$(Online supplement, Fig. S9).

The stoichiometry of the reaction was determined by measuring the absorbance of residual $\mathrm{BB}^{-}$at $\lambda_{\text {max }}=555 \mathrm{~nm}$, for a series of solutions containing a fixed initial concentration of dye with varied concentrations of oxidant. The [dye]:[oxidant] ratio was found to be $1: 6( \pm 10 \%)$. Thus, taking into consideration the oxidation products, the stoichiometric equation for the overall reaction is proposed as:

$2 \mathrm{BB}^{-}+6 \mathrm{HOCl}+2 \mathrm{H}_{2} \mathrm{O} \rightarrow \mathrm{P}_{1}+2 \mathrm{P}_{2}^{-}+\mathrm{P}_{3}+5 \mathrm{HCl}$

where the products are 4-(4-ethoxyphenylamino)benzoic acid $\left(\mathrm{P}_{1}\right)$, 3-[(ethyl-hydroxyamino)methyl]benzene sulfonate ion $\left(\mathrm{P}_{2}^{-}\right)$and $6^{\prime}$-chloro-5'-hydroxy-bicyclohexylidene-2,5,2' $4,4^{\prime}$-dione $\left(\mathrm{P}_{3}\right)$.

\subsection{Kinetic Studies}

All the reactions were studied with low initial concentrations of the dye and excess concentrations of all the other reagents. The reaction progress for depletion of [dye] was followed by monitoring the change in its absorbance at $555 \mathrm{~nm}$.

Figure 1 shows the repetitive spectra illustrating the depletion of dye as a function of time in a typical reaction with $\left[\mathrm{BB}^{-}\right]_{0}=$ $7.0 \times 10^{-5} \mathrm{M},\left[\mathrm{OCl}^{-}\right]_{0}=1.45 \times 10^{-3} \mathrm{M}$ and $\mathrm{pH}=9.0$. Figure 2 shows the typical depletion curves of $\mathrm{BB}^{-}$, with $\left[\mathrm{BB}^{-}\right]_{0}=7.0 \times 10^{-5} \mathrm{M}$, at varied $\left[\mathrm{OCl}^{-}\right]_{0}$ and constant ionic strength $(0.0128 \mathrm{M})$ at an initial $\mathrm{pH}$ of 9.0 .

The ln absorbance versus time plots were straight lines confirming the order with respect to dye is unity. The pseudofirst-order rate constant, $\mathrm{k}^{\prime}$, values obtained by analysing the respective kinetic curves for different initial hypochlorite concentrations are summarized in Table 1. Further, the plot of $1 n$ $\mathrm{k}^{\prime}$ versus $\ln \left[\mathrm{OCl}^{-}\right]$is linear with a slope of $1.03\left(R^{2}=0.97\right)$, suggesting that at $\mathrm{pH} 9.0$, the order with respect to hypochlorite ion is one.

\subsubsection{Effect of $\mathrm{pH}$ on the Reaction Rate}

As $\mathrm{pH}$ is an important parameter that controls the characteris-

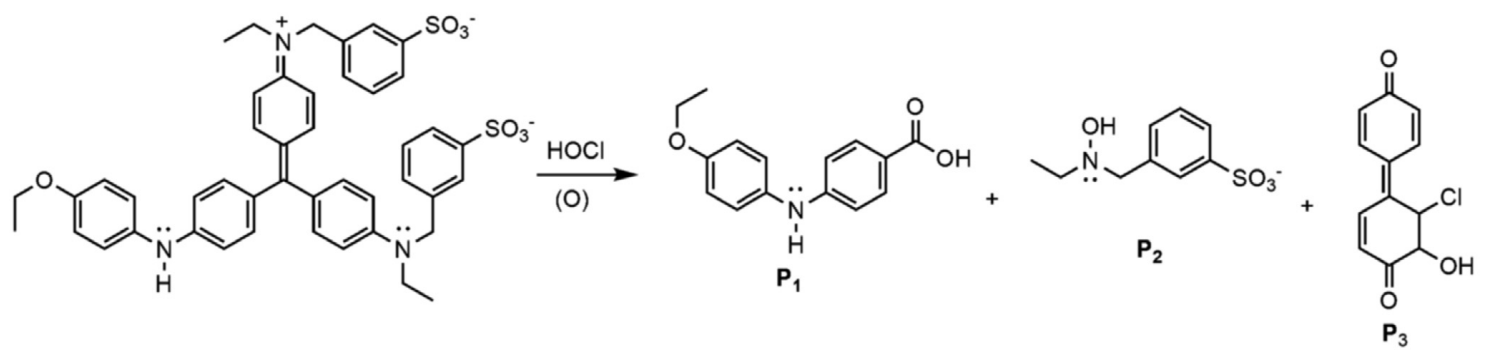

Scheme 1

Oxidation products of Brilliant Blue-R. 


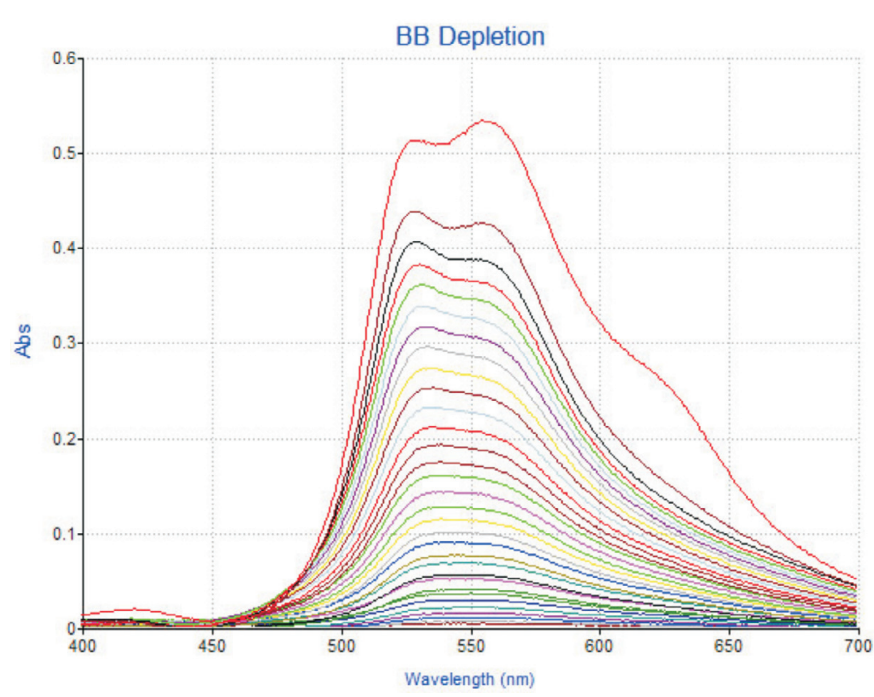

Figure 1 Brilliant Blue-R depletion profile ( $50 \mathrm{scans} / \mathrm{min}$ ) for the reaction of $\left[\mathrm{BB}^{-}\right]_{0}\left(7.0 \times 10^{-5} \mathrm{M}\right)$ with $\left[\mathrm{OCl}^{-}\right]_{0}\left(1.45 \times 10^{-3} \mathrm{M}\right),\left[\mathrm{H}^{+}\right]_{0}\left(9.96 \times 10^{-9} \mathrm{M}\right)$ and I $(0.012 \mathrm{M})$.

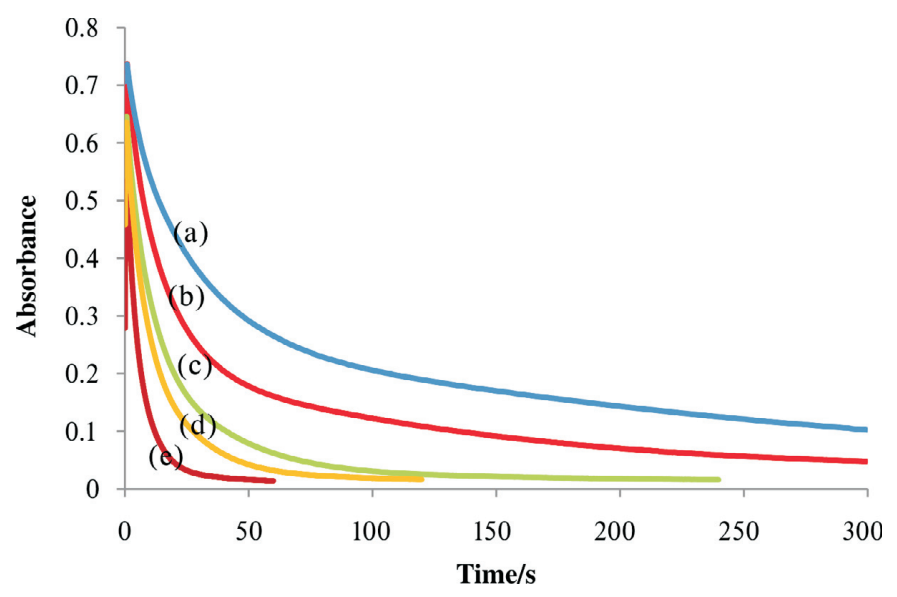

Figure 2 Depletion of Brilliant Blue-R with various hypochlorite concentrations for the reaction of $\left[\mathrm{BB}^{-}\right]_{0}\left(7.0 \times 10^{-5} \mathrm{M}\right)$ with $\left[\mathrm{OCl}^{-}\right]_{0} \times 10^{-3} / \mathrm{M}(\mathrm{a}=$ $0.73, \mathrm{~b}=1.45, \mathrm{c}=2.18, \mathrm{~d}=2.90$ and $\mathrm{e}=4.35)$ at $\mathrm{pH} 9.0$ and $\mathrm{I}(0.012 \mathrm{M})$.

tics of the dye, the effect of $\mathrm{pH}$ on the depletion kinetics of [BB'] at constant ionic strength was examined in the $\mathrm{pH}$ range of 4.0 -13.0. The $\ln \mathrm{k}^{\prime}$ versus $\ln \left[\mathrm{H}^{+}\right]$plot gave a slope of $0.27\left(R^{2}=0.96\right)$. The observed partial reaction order with respect to $\mathrm{H}^{+}$clearly suggests that acid may not be directly involved in the ratelimiting step. This can be well explained in terms of a dynamic equilibrium between the two oxidizing species, i.e. $\mathrm{OCl}^{-}+\mathrm{H}^{+} \leftrightharpoons$ $\left.\mathrm{HOCl}\left(\mathrm{pK}_{\mathrm{a}}=7.4\right)\right)^{23,24}$ With their presence, the oxidation of dye occurs simultaneously with $\mathrm{OCl}^{-}$and $\mathrm{HOCl}^{9}$ The observed enhanced $\mathrm{k}^{\prime}$ values with decreasing $\mathrm{pH}$ suggest that the rate of

Table 1 The reaction between Brilliant Blue- $\mathrm{R}$ and hypochlorite at constant ionic strength $\left(\left[\mathrm{BB}^{-}\right]_{0}=7.0 \times 10^{-5} \mathrm{M},\left[\mathrm{OCl}^{-}\right]_{0}=0.725 \times 10^{-3}-4.35 \times\right.$ $\left.10^{-3} \mathrm{M}, \mathrm{pH}=9.0, \mathrm{I}=0.0128 \mathrm{M}\right)$.

\begin{tabular}{cc}
\hline$\left[\mathrm{OCl}^{-}\right]_{0} / 10^{-3} \mathrm{M}$ & $\mathrm{k}^{\prime} / \mathrm{s}^{-1 *}$ \\
\hline 0.73 & 0.012 \\
1.45 & 0.030 \\
2.18 & 0.037 \\
2.90 & 0.046 \\
4.35 & 0.086 \\
\hline
\end{tabular}

${ }^{*}$ Mean of three replicate experiments with relative standard deviation $<5 \%$. oxidation by $\mathrm{HOCl}$ is much faster than by the $\mathrm{OCl}^{-}$ion. Of the chlorine-containing disinfecting agents, hypochlorous acid has the higher oxidation potential $\left(\mathrm{E}^{\circ}=1.44 \mathrm{~V}\right)$ than $\mathrm{OCl}^{-}\left(\mathrm{E}^{\circ}=\right.$ $0.90 \mathrm{~V}) .{ }^{25}$ On the assumption of the occurrence of two competitive reactions, the kinetics data was analysed to estimate the rate constants for the two competitive pseudo-first-order reactions. A perusal of Fig. 3 shows that the computed curve for the occurrence of the two pseudo-first-order reactions agreed fairly well with the experimental kinetic data, as judged by the negligible residual values.

The pseudo-first-order rate constants obtained at different $\mathrm{pH}$ conditions are summarized in Table 2 , where $\mathrm{k} 1^{\prime}$ represents the pseudo-first-order rate constant for the $\mathrm{OCl}^{-}$initiated oxidation and $\mathrm{k} 2$ ' represents the corresponding value for the reaction by $\mathrm{HOCl}$. Table 2 also includes the calculated equilibrium concentrations for $\mathrm{H}+, \mathrm{OCl}^{-}$and $\mathrm{HOCl}$ for initial conditions at different $\mathrm{pH}$ values which were computed by using the $\mathrm{pKa}=$ 7.4 .

An examination of the data in Table 2 suggests that, with increasing acid concentration, the $\mathrm{k}_{1}{ }^{\prime}$ values show a decreasing trend, while the $k_{2}^{\prime}$ values increase. The mean values of the second-order rate constants for the $\mathrm{OCl}^{-}$and $\mathrm{HOCl}$ initiated oxidations were $\mathrm{k}_{1}=1.2 \pm 0.2 \mathrm{M}^{-1} \mathrm{~s}^{-1}$ and $\mathrm{k}_{2}=22.0 \pm 1.2 \mathrm{M}^{-1} \mathrm{~s}^{-1}$, respectively (Table 2). The $\ln -\mathrm{ln}$ plots of $\mathrm{k}_{1}{ }^{\prime}$ and $\left[\mathrm{OCl}^{-}\right]_{\mathrm{eq}}$ and $\mathrm{k}_{2}^{\prime}$ and $[\mathrm{HOCl}]_{\mathrm{eq}}$ gave straight lines (with $R^{2}>0.97$ ). At low $\mathrm{pH}$ conditions, $\left[\mathrm{OCl}^{-}\right]_{\text {eq }}$ will be negligible and the pseudofirst-order conditions do not prevail under those conditions. These results confirm that acid influences the reaction rates by shifting the equilibrium between $\mathrm{OCl}^{-}$and $\mathrm{HOCl}$. Further increase in $\left[\mathrm{H}^{+}\right]$below $\mathrm{pH} 3$ exerted marginal increases in the reaction rate as at those $\mathrm{pH}$ conditions, all the oxidant already exists in the $\mathrm{HOCl}$ form only

\subsubsection{Kinetic Salt Effect at $p H 9.0$ and 4.0}

The influence of the ionic strength on the oxidation of $\mathrm{BB}^{-}$was examined at various ionic strengths (I), between 0.01 and $0.04 \mathrm{M}$, and at fixed initial concentrations of hypochlorite. At $\mathrm{pH} 9.0$, $85 \%$ of the oxidant exists in the form of the hypochlorite anion and $15 \%$ as $\mathrm{HOCl}^{23,24}$ Hence, the kinetic curves were analyzed for the occurrence of two consecutive reactions and the results obtained are summarized in Table 3 . The plot of $\log k$ versus $\mathrm{I}^{1 / 2}$ data at $\mathrm{pH} 9.0$ gave a linear curve with a slope of $1.03\left(R^{2}=0.99\right)$ suggesting that under alkaline $\mathrm{pH}$, the rate-limiting step involves species of like charges, possibly $\mathrm{BB}^{-}$and $\mathrm{OCl}^{-}$ions.

At $\mathrm{pH} 4.0,99 \%$ of the oxidant will be in the form of the neutral species, $\mathrm{HOCl}^{23,24}$ Thus, a linear relationship between the $\log \mathrm{k}^{\prime}$ and ionic strength can be anticipated theoretically. A plot of $\log \mathrm{k}^{\prime}$ versus I gave a linear curve with a gradient of $0.5\left(R^{2}=0.99\right)$, confirming that at acidic $\mathrm{pH} 4$, the rate-limiting reaction involves a neutral molecule $(\mathrm{HOCl})$ and a charged species $\left(\mathrm{BB}^{-}\right)$possibly

\subsubsection{Activation Parameters}

The energy parameters provide valuable information about the nature of the transition state and the reaction mechanism. ${ }^{1}$ The kinetics of $\mathrm{BB}^{-}$oxidation were measured over the temperature range of $298-313 \mathrm{~K}$ at $\mathrm{pH} 9.0$ to establish the energy parameters for the $\mathrm{HOCl}$ and $\mathrm{OCl}^{-}$driven reactions. ${ }^{26,27}$ Table 4 summarizes the determined rate constants for the oxidation of $\mathrm{BB}^{-}$at different temperatures. The $\Delta \mathrm{H}^{\ddagger}$ values at $25^{\circ} \mathrm{C}$ were estimated to be $33.1 \mathrm{~kJ} \mathrm{~mol}^{-1}$ and $26.8 \mathrm{~kJ} \mathrm{~mol}^{-1}$ for the $\mathrm{OCl}^{-}$and $\mathrm{HOCl}$ initiated reactions, respectively. The $\mathrm{HOCl}$ initiated reaction had a slightly lower energy of activation $\left(29.3 \pm 0.1 \mathrm{~kJ} \mathrm{~mol}^{-1}\right)$ compared with the $\mathrm{OCl}^{-}$initiated reaction $\left(35.5 \pm 0.1 \mathrm{~kJ} \mathrm{~mol}^{-1}\right)$. The large negative entropy values $\left(\Delta \mathrm{S}^{\ddagger}\right)$ of -191.9 and $-204.6 \mathrm{~J} \mathrm{~K}^{-1}$ 

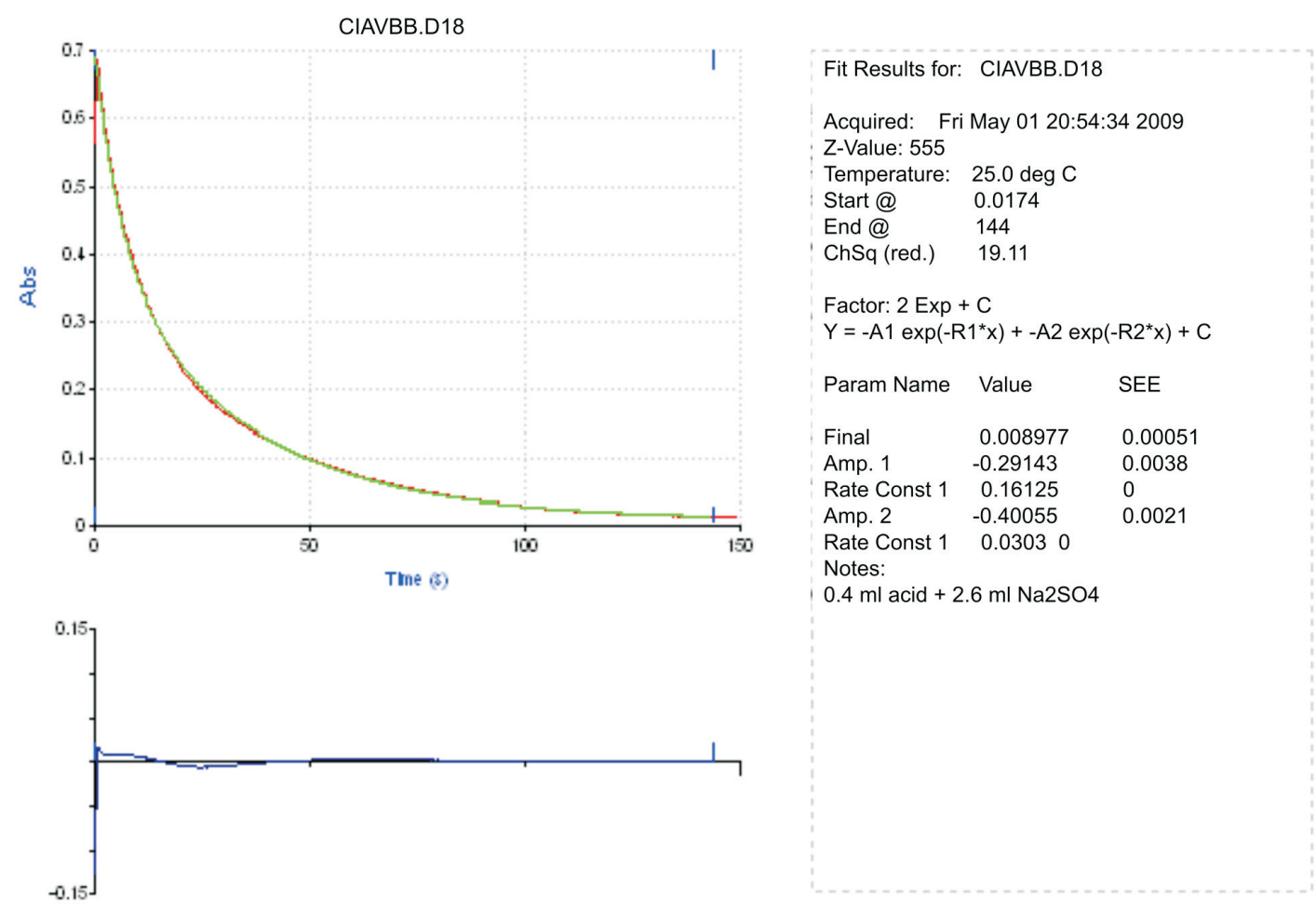

Figure 3 KinetAsyst ${ }^{\mathrm{TM}}$ double-exponential equation fit of two curves and residuals for two competitive first-order reactions (lower sketch) for the reaction of $\left[\mathrm{BB}^{-}\right]_{0}\left(7.0 \times 10^{-5} \mathrm{M}\right)$ with $\left[\mathrm{OCl}^{-}\right]_{0}\left(1.45 \times 10^{-3} \mathrm{M}\right),\left[\mathrm{H}^{+}\right]_{0}\left(9.96 \times 10^{-9} \mathrm{M}\right)$ and $\mathrm{I}(0.012 \mathrm{M})$.

Table 2 Effect of acid on the speciation of hypochlorite and reaction rate.

\begin{tabular}{cccccccc}
\hline $\mathrm{pH}$ & {$\left[\mathrm{H}^{+}\right] \mathrm{M}$} & {$\left[\mathrm{OCl}^{-}\right]_{\mathrm{eq}} / \mathrm{M}$} & {$[\mathrm{HOCl}]_{\mathrm{eq}} / \mathrm{M}$} & $\mathrm{k}_{1}{ }^{\prime} / \mathrm{s}^{-1 *}$ & $\mathrm{k}_{2}{ }^{\prime} / \mathrm{s}^{-1 *}$ & $\mathrm{k}_{1} / \mathrm{M}^{-1} \mathrm{~s}^{-1}$ & $\mathrm{k}_{2} / \mathrm{M}^{-1} \mathrm{~s}^{-1}$ \\
\hline 8.70 & $1.99 \times 10^{-9}$ & $2.76 \times 10^{-2}$ & $1.34 \times 10^{-3}$ & 0.0390 & 0.0270 & 1.41 & 20.08 \\
8.35 & $4.45 \times 10^{-9}$ & $2.61 \times 10^{-2}$ & $2.85 \times 10^{-3}$ & 0.0360 & 0.0610 & 1.37 & 21.43 \\
8.00 & $9.97 \times 10^{-9}$ & $2.33 \times 10^{-2}$ & $5.68 \times 10^{-3}$ & 0.0303 & 0.1400 & 1.29 & 24.64 \\
7.70 & $1.99 \times 10^{-8}$ & $1.95 \times 10^{-2}$ & $9.49 \times 10^{-3}$ & 0.0250 & 0.2050 & 1.28 & 21.61 \\
7.45 & $3.54 \times 10^{-8}$ & $1.55 \times 10^{-2}$ & $1.34 \times 10^{-2}$ & 0.0190 & 0.2799 & 1.22 & 20.81 \\
7.20 & $6.29 \times 10^{-8}$ & $1.14 \times 10^{-2}$ & $1.76 \times 10^{-2}$ & 0.0135 & 0.3670 & 1.18 & 20.88 \\
7.00 & $9.97 \times 10^{-8}$ & $8.43 \times 10^{-3}$ & $2.06 \times 10^{-2}$ & 0.0094 & 0.4275 & 1.12 & 20.79 \\
6.75 & $1.77 \times 10^{-7}$ & $5.43 \times 10^{-3}$ & $2.36 \times 10^{-2}$ & 0.0060 & 0.4930 & 1.10 & 20.92 \\
6.50 & $3.15 \times 10^{-7}$ & $3.32 \times 10^{-3}$ & $2.57 \times 10^{-2}$ & 0.0035 & 0.5390 & 1.05 & 21.00 \\
6.00 & $9.98 \times 10^{-7}$ & $1.14 \times 10^{-3}$ & $2.79 \times 10^{-2}$ & 0.0011 & 0.5880 & 1.00 & 21.11 \\
5.40 & $3.97 \times 10^{-6}$ & $2.94 \times 10^{-4}$ & $2.87 \times 10^{-2}$ & 0.0002 & 0.6459 & 0.84 & 22.50 \\
3.70 & $1.99 \times 10^{-4}$ & $5.95 \times 10^{-6}$ & $2.90 \times 10^{-2}$ & - & 0.6582 & - & 22.70 \\
3.31 & $4.89 \times 10^{-4}$ & $2.42 \times 10^{-6}$ & $2.90 \times 10^{-2}$ & - & 0.6652 & - & 22.94 \\
3.29 & $5.12 \times 10^{-4}$ & $2.32 \times 10^{-6}$ & $2.90 \times 10^{-2}$ & - & 0.6725 & - & 23.19 \\
3.22 & $6.02 \times 10^{-4}$ & $1.97 \times 10^{-6}$ & $2.90 \times 10^{-2}$ & - & 0.6842 & - & 23.59 \\
3.11 & $7.75 \times 10^{-4}$ & $1.53 \times 10^{-6}$ & $2.90 \times 10^{-2}$ & - & 0.6910 & - & 23.83 \\
Mean and standard deviation & & & & & $1.2 \pm 0.2$ & $22.0 \pm 1.2$ \\
\hline
\end{tabular}

* Mean of four replicate experiments with relative standard deviation $<5 \% . \mathrm{k}_{1}{ }^{\prime}$ and $\mathrm{k}_{2}{ }^{\prime}$ are the $p s e u d o$-first-order rate constants with respect to $\mathrm{OCl}^{-}$and $\mathrm{HOCl}$ respectively.

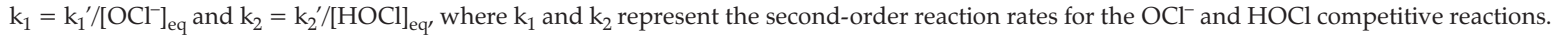

Table 3 Effect of ionic strength on the reaction rate $\left(\left[\mathrm{OCl}^{-}\right]_{0}=1.45 \times 10^{-3}\right.$ $\left.\mathrm{M},\left[\mathrm{BB}^{-}\right]_{0}=7.0 \times 10^{-5} \mathrm{M}, \mathrm{pH}=9.0\right)$.

\begin{tabular}{ccc}
\hline Ionic strength $/ \mathrm{M}$ & $\mathrm{k}_{1}{ }^{\prime} / \mathrm{s}^{-1 *}$ & $\mathrm{k}_{2}{ }^{\prime} / \mathrm{s}^{-1 *}$ \\
\hline 0.0099 & 0.035 & 0.045 \\
0.0188 & 0.035 & 0.045 \\
0.0225 & 0.037 & 0.047 \\
0.0263 & 0.038 & 0.048 \\
0.0338 & 0.040 & 0.049 \\
\hline
\end{tabular}

* Mean of three replicate experiments with relative standard deviation $<5 \%$.
Table 4 Rate constants for the $\mathrm{BB}^{-}$oxidation as function of temperature $\left(\left[\mathrm{BB}^{-}\right]_{0}=7.0 \times 10^{-5} \mathrm{M},\left[\mathrm{OOCl}^{-}\right]_{0}=1.45 \times 10^{-3} \mathrm{M}\right.$ at $\left.\mathrm{pH} 9.0\right)$.

\begin{tabular}{lcccc}
\hline Temp./K & $\mathrm{k}_{1}{ }^{\prime} / \mathrm{s}^{-1 *}$ & $\mathrm{k} \mathrm{M}^{-1} / \mathrm{s}^{-1}$ & $\mathrm{k}_{2}{ }^{\prime} / \mathrm{s}^{-1 *}$ & $\mathrm{k} \mathrm{M}^{-1} / \mathrm{s}^{-1}$ \\
\hline 283 & 0.014 & 1.21 & 0.041 & 3.56 \\
288 & 0.019 & 1.65 & 0.058 & 5.04 \\
293 & 0.028 & 1.65 & 0.064 & 5.56 \\
298 & 0.033 & 2.86 & 0.079 & 6.86 \\
303 & 0.037 & 3.21 & 0.098 & 8.52 \\
\hline
\end{tabular}

* Mean of three replicate runs with relative standard deviation $<5 \% . \mathrm{k}=$ $\mathrm{k}^{\prime} /\left[\mathrm{OCl}^{-}\right]\left[\mathrm{H}^{+}\right]$. 
$\mathrm{mol}^{-1}$ for the $\mathrm{OCl}^{-}$and $\mathrm{HOCl}$ initiated reactions respectively suggest that the activated complexes formed are compact in nature with a precise configuration. ${ }^{20}$

\subsubsection{Rate Laws}

The first-order dependence of the reaction rate on the reactants and the observed salt effect at $\mathrm{pH} 9$ and $\mathrm{pH} 4$ suggest that the rate-limiting steps for the two competitive reactions involve one each of $\mathrm{BB}^{-}$and $\mathrm{OCl}^{-}$ions and $\mathrm{BB}^{-}$and $\mathrm{HOCl}$, respectively. Thus, the major pathways of the reaction involve $\mathrm{OCl}^{-}$or $\mathrm{HOCl}$ forming an activated complex, which undergoes decomposition, to form the intermediates and products. The intermediates further undergo oxidation to give the products. Based on these findings the rate law is proposed as:

Rate $=\mathrm{k}_{1}\left[\mathrm{OCl}^{-}\right]\left[\mathrm{BB}^{-}\right]+\mathrm{k}_{2}[\mathrm{HOCl}]\left[\mathrm{BB}^{-}\right]$,

where $\mathrm{k}_{1}$ and $\mathrm{k}_{2}$ represent the rate constants facilitated by $\mathrm{OCl}^{-}$ and $\mathrm{HOCl}$, respectively.

$\mathrm{r}=\left\{\mathrm{k}_{1}\left[\mathrm{OCl}^{-}\right]+\mathrm{k}_{2}[\mathrm{HOCl}]\right\}\left[\mathrm{BB}^{-}\right]=\left\{\mathrm{k}_{1}^{\prime}+\mathrm{k}_{2}{ }^{\prime}\right\}\left[\mathrm{BB}^{-}\right]=\mathrm{k}^{\prime}\left[\mathrm{BB}^{-}\right]$ where the pseudo-first-order rate constant, $\mathrm{k}^{\prime}$ equals to $\left\{\mathrm{k}_{1}{ }^{\prime}+\right.$ $\left.\mathrm{k}_{2}{ }^{\prime}\right\}$, while $\mathrm{k}_{1}=\mathrm{k}_{1}{ }^{\prime} /\left[\mathrm{OCl}^{-}\right]_{0}$ and $\mathrm{k}_{2}=\mathrm{k}_{2}{ }^{\prime} /[\mathrm{HOCl}]_{0}, \mathrm{k}_{1}{ }^{\prime}$ and $\mathrm{k}_{2}{ }^{\prime}$ represent the pseudo-first-order rate constants with respect to hypochlorite and $\mathrm{HOCl}$.

\subsubsection{Reaction Scheme}

A plausible reaction scheme for the oxidation of $\mathrm{BB}^{-}$is presented in Scheme 2. An electron flow originating from the lone pair on the tertiary nitrogen toward the oxygen of the $\mathrm{HOCl}$ molecule, results in the addition of a hydroxyl group to the Brilliant Blue-R, intermediate, $\mathrm{I}_{1}$. Electrons from the $\pi$ bond in the alkene then form a cyclopropane cation with the concomitant loss of the hydroxyl group resulting in $\mathrm{I}_{2}$. A hydroxyl ion then attacks the cation resulting in $\mathrm{I}_{3}$, from which a proton is abstracted from the hydroxyl group on the cyclopropane ring, resulting in the concurrent opening of the ring to produce $\mathrm{I}_{4}$. A hydroxyl ion subsequently attacks the carbonyl group, which ultimately results in $\mathrm{P}_{1}$ and the intermediate $\mathrm{I}_{5}$.

The lone pair of the nitrogen in $I_{5}$ attacks the oxygen of a further $\mathrm{HOCl}$ molecule, resulting in a hydroxy group being attached to the nitrogen in the cationic intermediate $\mathrm{I}_{6}$. A water molecule splits the amine portion of $\mathrm{I}_{6}$ from the rest of the molecule, resulting in the product $\mathrm{P}_{2}$ and the intermediate $\mathrm{I}_{7}$. Subsequently, a chloride ion removes a proton from the protonated oxygen to give rise to the neutral intermediate $\mathrm{I}_{8}$. The lone pair on the nitrogen in $\mathrm{I}_{8}$ attacks the oxygen of a $\mathrm{HOCl}$ molecule, resulting in $\mathrm{N}$-hydroxylation in $\mathrm{I}_{9}$. Cleavage of the hydroxylamine as occurred previously by the attack of a water molecule results in $\mathrm{I}_{10}$ and the product $\mathrm{P}_{3}$. Removal of a proton from the aromatic hydroxyl of $\mathrm{I}_{10}$ with a concurrent flow of electrons toward the oxygen at the other end results in the benzoquinone intermediate $\mathrm{I}_{11}$. Addition of a $\mathrm{HOCl}$ molecule across the double bond results in the product $\mathrm{P}_{4}$. While the equilibrium between $\mathrm{OCl}^{-}$and $\mathrm{HOCl}$ is maintained, the reaction with hypochlorite occurs along similar lines as with $\mathrm{HOCl}$ to a large extent, but at a relatively slow rate. The minor differences due to protonation and deprotonation of intermediates and products is accommodated in the simulations.

\subsubsection{Reaction Mechanism}

Based on the reaction stoichiometry estimated, and the major products identified, the mechanism for the reaction of Brilliant Blue-R with hypochlorite can be expressed in the following steps:

$$
\begin{array}{ll}
\mathrm{H}^{+}+\mathrm{OCl}^{-} \leftrightharpoons \mathrm{HOCl} & \mathrm{R} 1 \\
\mathrm{HOCl}+\mathrm{Cl}^{-}+\mathrm{H}^{+} \leftrightharpoons \mathrm{L} \mathrm{Cl}_{2}+\mathrm{H}_{2} \mathrm{O} & \mathrm{R} 2 \\
\mathrm{BB}^{-}+\mathrm{OCl}^{-} \rightarrow \mathrm{P}_{1}+\mathrm{I}_{5}^{2-}+\mathrm{H}^{+}+\mathrm{Cl}^{-} & \mathrm{R} 3 \\
\mathrm{BB}^{-}+\mathrm{HOCl} \rightarrow \mathrm{P}_{1}+\mathrm{I}_{5}^{2-}+2 \mathrm{H}^{+}+\mathrm{Cl}^{-} & \mathrm{R} 4 \\
\mathrm{I}_{5}^{2-}+\mathrm{HOCl} \rightarrow \mathrm{I}_{7}+\mathrm{P}_{2}^{-}+\mathrm{Cl}^{-} & \mathrm{R} 5 \\
\mathrm{I}_{7}+\mathrm{HOCl} \rightarrow \mathrm{I}_{10}+\mathrm{H}^{+}+\mathrm{P}_{2}^{-}+\mathrm{H}^{+}+\mathrm{Cl}^{-} & \mathrm{R} 6 \\
\mathrm{I}_{10}+\mathrm{HOCl} \rightarrow \mathrm{I}_{11}+\mathrm{H}^{+}+\mathrm{Cl}^{-} & \mathrm{R} 7 \\
\mathrm{I}_{11}+\mathrm{HOCl} \rightarrow \mathrm{I}_{13}+\mathrm{H}^{+}+\mathrm{Cl}^{-} & \mathrm{R} 8 \\
\mathrm{I}_{13}+\mathrm{HOCl} \rightarrow \mathrm{P}_{3} & \mathrm{R} 9 \\
\text { The overall reaction mechanism is: } & \\
2 \mathrm{BB}^{-}+6 \mathrm{HOCl}+2 \mathrm{H}_{2} \mathrm{O} \rightarrow \mathrm{P}_{1}+2 \mathrm{P}_{2}^{-}+\mathrm{P}_{3}+5 \mathrm{HCl}
\end{array}
$$

where $P_{1}$ is 4-(4-ethoxyphenylamino)benzoic acid; $P_{2}$ is 3-[(ethylhydroxyamino)methyl]- benzene sulfonic acid, and $\mathrm{P}_{3}$ is 6'-chloro-5'-hydroxy-bicyclohexylidene-2,5,2'-triene-4,4'-dione.

\subsubsection{Simulation Studies}

The Simkine 3 software ${ }^{28-30}$ was used to simulate the complex multi-step mechanism for the reaction between $\mathrm{BB}^{-}$and the oxidants, by utilizing the proposed mechanism and the experimentally obtained rate coefficients. For the simulations all the steps involving the formation of intermediates, which undergo consecutive reactions with intermediates or other oxidative species were considered. In each elementary step, the overall charge and mass balances were strictly accounted for (Table 5).

The rate constants experimentally obtained were employed for reactions steps $\mathrm{R} 3$ and $\mathrm{R} 4$. The rate-limiting step of the oxidation mechanism involves the steps initiated by $\mathrm{OCl}^{-}$and/or

\begin{tabular}{|c|c|c|c|}
\hline Reaction No. & Reaction mechanism & Forward rate & Reverse rate \\
\hline R1 & $\mathrm{H}^{+}+\mathrm{OCl}^{-} \leftrightharpoons \mathrm{HOCl}$ & $3.97 \times 10^{-4} \mathrm{M}^{-1} \mathrm{~s}^{-1}$ & $1.0 \times 10^{-4} \mathrm{~s}^{-1}$ \\
\hline $\mathrm{R} 2$ & $\mathrm{HOCl}+\mathrm{Cl}^{-}+\mathrm{H}^{+} \leftrightharpoons \mathrm{Cl}_{2}$ & $3.63 \times 10^{-3} \mathrm{M}^{-2} \mathrm{~s}^{-1}$ & $1.1 \mathrm{~s}^{-1}$ \\
\hline R3 & $\mathrm{BB}^{-}+\mathrm{HOCl} \rightarrow \mathrm{I}_{1}^{2-}+\mathrm{P}_{1}^{+}$ & $2.2 \times 10^{1} \mathrm{M}^{-1} \mathrm{~s}^{-1}$ & - \\
\hline R5 & $\mathrm{BB}^{-}+\mathrm{OCl}^{-} \rightarrow \mathrm{I}_{1}^{2-}$ & $1.22 \mathrm{M}^{-1} \mathrm{~s}^{-1}$ & - \\
\hline R6 & $\mathrm{I}_{1}^{2-}+\mathrm{H}^{+} \rightarrow \mathrm{I}_{1}+\mathrm{P}_{1}^{-}$ & $3.30 \times 10^{9} \mathrm{M}^{-1} \mathrm{~s}^{-1}$ & - \\
\hline R7 & $\mathrm{I}_{1}+\mathrm{HOCl} \rightarrow \mathrm{I}_{2}^{+}+\mathrm{OCl}^{-}$ & $2.30 \times 10^{9} \mathrm{M}^{-1} \mathrm{~s}^{-1}$ & - \\
\hline R8 & $\mathrm{I}_{2}^{+}+\mathrm{OCl}^{-} \rightarrow \mathrm{I}_{3}+\mathrm{P}_{2}$ & $4.30 \times 10^{9} \mathrm{M}^{-1} \mathrm{~s}^{-1}$ & - \\
\hline R9 & $\mathrm{I}_{3}^{+}+\mathrm{HOCl} \rightarrow \mathrm{I}_{4}+\mathrm{H}^{+}$ & $3.41 \times 10^{9} \mathrm{M}^{-1} \mathrm{~s}^{-1}$ & - \\
\hline R10 & $\mathrm{I}_{4}+\mathrm{HOCl} \rightarrow \mathrm{I}_{3}+\mathrm{OH}^{-}+\mathrm{P}_{2}^{+}$ & $3.01 \times 10^{8} \mathrm{M}^{-1} \mathrm{~s}^{-1}$ & - \\
\hline R11 & $\mathrm{I}_{3} \rightarrow \mathrm{P}_{3}+3 \mathrm{HCl}$ & $4.17 \times 10^{8} \mathrm{~s}^{-1}$ & - \\
\hline
\end{tabular}
$\mathrm{HOCl}$ on $\mathrm{BB}^{-}$leading to the formation of the reactive intermediate. The reactions $\mathrm{R} 3$ and $\mathrm{R} 4$ are the rate-controlling steps for dye oxidation. Literature data were used for R1 and $\mathrm{R} 2$ and for the reaction equilibrium between $\mathrm{OCl}^{-}$and $\mathrm{HOCl}^{23,31}$ and the values used for R5 to R13 were estimated rate constants from the simulations. The estimated rate constants were optimized so that the simulated curves matched the experimental curves. The rate constants were initially adjusted manually to test the sensitivity and importance of the elementary reactions. Reactions R5 to R13

Table 5 Forward and reverse rate constants obtained from literature and simulations. 
show the consecutive steps for further oxidation of the reactive intermediates by different species and R8, R12 and R13 represent the reactions leading to the different products identified.

Figure 4 shows the experimental curves for depletion of the dye at different oxidant concentrations and the corresponding simulated curves for those conditions. The experimental and simulated curves are in good agreement. Furthermore, Fig. 5 shows the profiles of the experimental and simulated curves for the depletion of Brilliant Blue-R at the chosen conditions and the profiles of the products and various intermediates as a function of time.

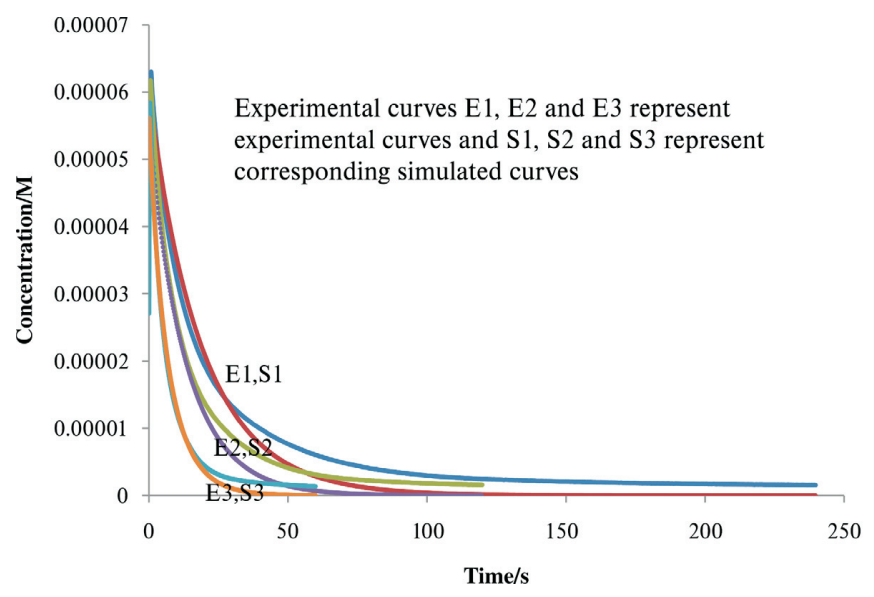

Figure 4 Experimental curves versus simulated curves for reaction of $\left[\mathrm{BB}^{-}\right]_{0}\left(7.0 \times 10^{-5} \mathrm{M}\right)$ with $\left[\mathrm{OCl}^{-}\right]_{0} \times 10^{-3} / \mathrm{M}=(\mathrm{E} 1=1.45, \mathrm{E} 2=2.90$ and $\mathrm{E} 3=4.35)$ at $\mathrm{pH} 9.0$ and $\mathrm{I}(0.012 \mathrm{M})$.

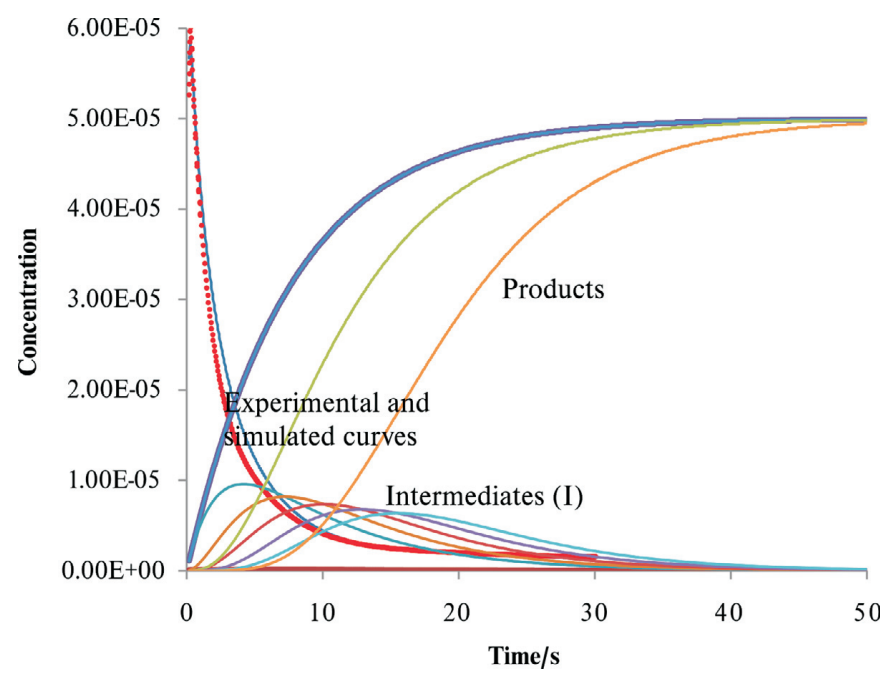

Figure 5 Intermediates and product formation for the reaction of Brilliant Blue-R with hypochlorite. $\left[\mathrm{BB}^{-}\right]_{0}\left(7.0 \times 10^{-5} \mathrm{M}\right)$ with $\left[\mathrm{OCl}^{-}\right]_{0}=4.35 \times$ $10^{-3} \mathrm{M}$.

\section{Conclusions}

The oxidation of $\mathrm{BB}^{-}$occurs through two competitive pathways facilitated by $\mathrm{OCl}^{-}$and $\mathrm{HOCl}$. The oxidation by $\mathrm{HOCl}$ is faster $\left(\mathrm{k}_{2}=22.0 \pm 1.2 \mathrm{M}^{-1} \mathrm{~s}^{-1}\right)$ and is the major pathway, relative to the reaction with $\mathrm{OCl}^{-}\left(\mathrm{k}_{1}=1.2 \pm 0.2 \mathrm{M}^{-1} \mathrm{~s}^{-1}\right)$. The ratedetermining steps involved the species $\mathrm{BB}^{-}+\mathrm{HOCl}$ and $\mathrm{BB}^{-}+$ $\mathrm{OCl}^{-}$. This was supported by the observed positive salt effect for the hypochlorite driven reaction and that $\mathrm{k}$ is proportional to I for the $\mathrm{HOCl}$-facilitated oxidation. The three main oxidation products were 4-(4-ethoxyphenylamino)benzoic acid, 3-[(ethylhydroxyamino)methyl] benzene sulfonic acid and 6'-chloro-5'hydroxy-bicyclohexylidene-2,5,2'-triene-4,4'-dione.

\section{Supplementary material}

The NMR and MS spectra of the new compounds are provided in the online supplement.

\section{Acknowledgements}

The authors are grateful for the financial support received from the University of KwaZulu-Natal and the National Research Foundation, Pretoria, South Africa.

\section{References}

1 A.D. Dhale and V.V. Mahajani, Reactive dye house wastewater treatment. Use of hybrid technology: membrane, sonication followed by wet oxidation. Ind. Eng. Chem. Res., 1999, 38, 2058-2064.

2 G. Paul, In Patterns of European Industrialization, Routledge, 1993.

3 S.B. Bukallah, M.A. Rauf and S.S. Ashraf, Photocatalytic decoloration of Coomassie Brilliant Blue with titanium oxide. Dyes Pigments, 2007, 72, 353-356.

4 J.J.F. Siqueira, I.N. Rôças, A. Favieri, and K.C. Lima, Chemomechanical reduction of the bacterial population in the root canal after instrumentation and irrigation with $1 \%, 2.5 \%$, and $5.25 \%$ sodium hypochlorite. J. Endodontics, 2000, 26, 331-334.

5 W. Rutala and D. Weber, Uses of inorganic hypochlorite (bleach) in health-care facilities. Clin. Microbiol. Rev., 1997, 10, 597-610.

6 J.-P. Zock, E. Plana, J.M. Antó, G. Benke, P.D. Blanc, A. Carosso, A. Dahlman-Höglund, J. Heinrich, D. Jarvis, H. Kromhout, L. Lillienberg, M.C. Mirabelli, D. Norbäck, M. Olivieri, M. Ponzio, K. Radon, A. Soon, M. van Sprundel, J. Sunyer, C. Svanes, K. Torén, G. Verlato, S. Villani and M. Kogevinas, Domestic use of hypochlorite bleach, atopic sensitization, and respiratory symptoms in adults. J. Allergy Clin. Immunol., 2009, 124, 731-738.

7 L. Szpyrkowicz, C. Juzzolino and S.N. Kaul, A comparative study on oxidation of disperse dyes by electrochemical process, ozone, hypochlorite and Fenton reagent. Water Res., 2001, 35, 2129-2136.

8 N. Mohan, N. Balasubramanian and C.A.Basha, Electrochemical oxidation of textile wastewater and its reuse. J. Hazard. Mater., 2007, $147,644-651$.

9 A.B. dos Santos,FJ. Cervantes and J.B. van Lier, Review paper on current technologies for decolourization of textile wastewaters: perspectives for anaerobic biotechnology. Bioresource Technol., 2007, 98, 23692385.

10 S.B. Jonnalagadda and S. Nadupalli, Effluent treatment using electrochemically bleached seawater - oxidative degradation of pollutants. Talanta, 2004, 64, 18-22.

11 S.B. Jonnalagadda and M.A. Salem, Chemistry of a non-linear reaction between Aniline Blue and acidic bromate. Phys. Chem. Chem. Phys., 1999, 1, 821-826.

12 S.B. Jonnalagadda, C. Chinake and R.H. Simoyi, Kinetics and mechanism of the reaction between Thymol Blue and bromate in acidic medium. J. Chem. Soc, Faraday Trans., 1995, 91, 1635-1640.

13 G.K. Muthakia and S.B. Jonnalagadda, Uncatalyzed and vanadium (V)-catalyzed reaction of methylene blue with potassium bromate in aqueous sulfuric acid. J. Phys. Chem., 1989, 93, 4751-4756.

14 P. Sawunyama and S.B. Jonnalagadda, Acridine orange-bromate reaction. A kinetic method for the analysis of V (V). J. Phys. Org. Chem., 1995, 8, 175-185.

15 S.B. Jonnalagadda, M. Shezi and N.R. Gollapalli, Kinetics and simulations of reaction between safranine-O and acidic bromate and role of bromide therein. International J. Chem. Kinetics, 2002, 34, 542-549.

16 A. Hariram, V. Govender and S.B. Jonnalagadda, Oxidative degradation of indogocarmine by hypochlorite - A tool for determination of hypochlorite in commercial samples. J. Env. Sci. Health, 2003, 38, 1055-1064.

17 S.B. Jonnalagadda, M. Shezi and B. Pare, Uncatalyzed and ruthenium (III)-catalyzed reaction of acidic chlorite with methylene violet. Intl. J. Chem. Kinetics, 2003, 35, 294-303.

18 L.Q. Qwabe,B. Pare and S.B. Jonnalagadda, Kinetics and mechanism of reaction of acidic chlorite with phenoxazine dyes, nile blue and meldola's blue. Bull. Chem. Soc. Ethiop., 2005, 19, 103-116.

19 S.B. Jonnalagadda and B.K. Pare, Oxidation of toluidine blue by chlorite in acid and mechanisms of the uncatalyzed and Ru (III)-cata- 
lyzed reactions: A kinetic approach. J. Phys. Chem. A, 2010, 114, 12162-12167.

20 S. Nadupalli, N. Koorbanally and S.B. Jonnalagadda, Kinetics and mechanism of the oxidation of amaranth with hypochlorite. J. Phys. Chem., A 2011, 115, 7948-7954.

21 S. Nadupalli, N. Koorbanally and S.B. Jonnalagadda, Chlorine dioxide-facilitated oxidation of the azo dye amaranth. J. Phys. Chem. A, 2011, 115, 11682-11688.

22 G. Peintler, I. Nagypal and I.R. Epstein, Systematic design of chemical oscillators. 60. Kinetics and mechanism of the reaction between chlorite ion and hypochlorous acid. J. Phys. Chem., 1990, 94, 2954-2958.

23 L.C. Adam, I. Fabian, K. Suzuki and G. Gordon, Hypochlorous acid decomposition in the $\mathrm{pH} 5-8$ region. Inorg. Chem., 1992, 31 3534-3541.

24 K. Kumar and D.W. Margerum, Kinetics and mechanism of generalacid-assisted oxidation of bromide by hypochlorite and hypochlorous acid. Inorg. Chem., 1987, 26, 2706-2711.

25 L. Szpyrkowicz, C. Juzzolino, S.N. Kaul, S. Daniele and M.D. De Faveri, Electrochemical oxidation of dyeing baths bearing disperse dyes. Ind. Eng. Chem. Res., 2000, 39, 3241-3248.
26 T.S. Anirudhan and P.G. Radhakrishnan, Thermodynamics and kinetics of adsorption of $\mathrm{Cu}$ (II) from aqueous solutions onto a new cation exchanger derived from tamarind fruit shell. J. Chem. Thermodynam., 2008, 40, 702-709.

27 O. Hübner and H.-J.Himmel, Physical Inorganic Chemistry, (A. Bakac, ed.). Angewandte Chemie International Edition 2011, 50, 1972-1973.

28 S.B. Jonnalagadda, N. Parumasur and M.N. Shezi, A user-friendly programme 'Simkine' for simulation of kinetics involving complex reaction mechanisms. Comp. Biol. Chem., 2003, 27, 147-152.

29 S.B. Jonnalagadda and M.N. Shezi, Simkine 2-versatile software for the computation of kinetic profiles of intricate chemical reaction mechanisms. S. Afr. J. Chem., 2006, 59, 82-85.

30 M.N. Shezi, and S.B. Jonnalagadda, Easy to use program 'Simkine 3' for simulating kinetic profiles of intricate chemical systems and optimizing predictable rate coefficients therein, Bull. Chem. Soc. Ethiop., 26(2), 2012, 267-277.

31 J. Oakes and P. Gratton, Kinetic investigations of the oxidation of arylazonaphthol dyes in hypochlorite solutions as a function of $\mathrm{pH}$. J. Chem. Soc., Perkin Trans., 2, 1998, 2201-2206. 
Kinetics and Mechanism of the Oxidation of Coomassie Brilliant Blue-R dye by Hypochlorite and Role of Acid there in.

Srinivasu Nadupalli, Venkata D.B.C. Dasireddy, Neil A. Koorbanally and Sreekantha B. Jonnalagadda*

School of Chemistry and Physics, University of KwaZulu-Natal, Westville Campus, Private Bag X54001, Durban 4000, South Africa

*Corresponding author: jonnalagaddas@ukzn.ac.za

Supplementary information: S. Afr. J. Chem., 2015, 68, 85-92

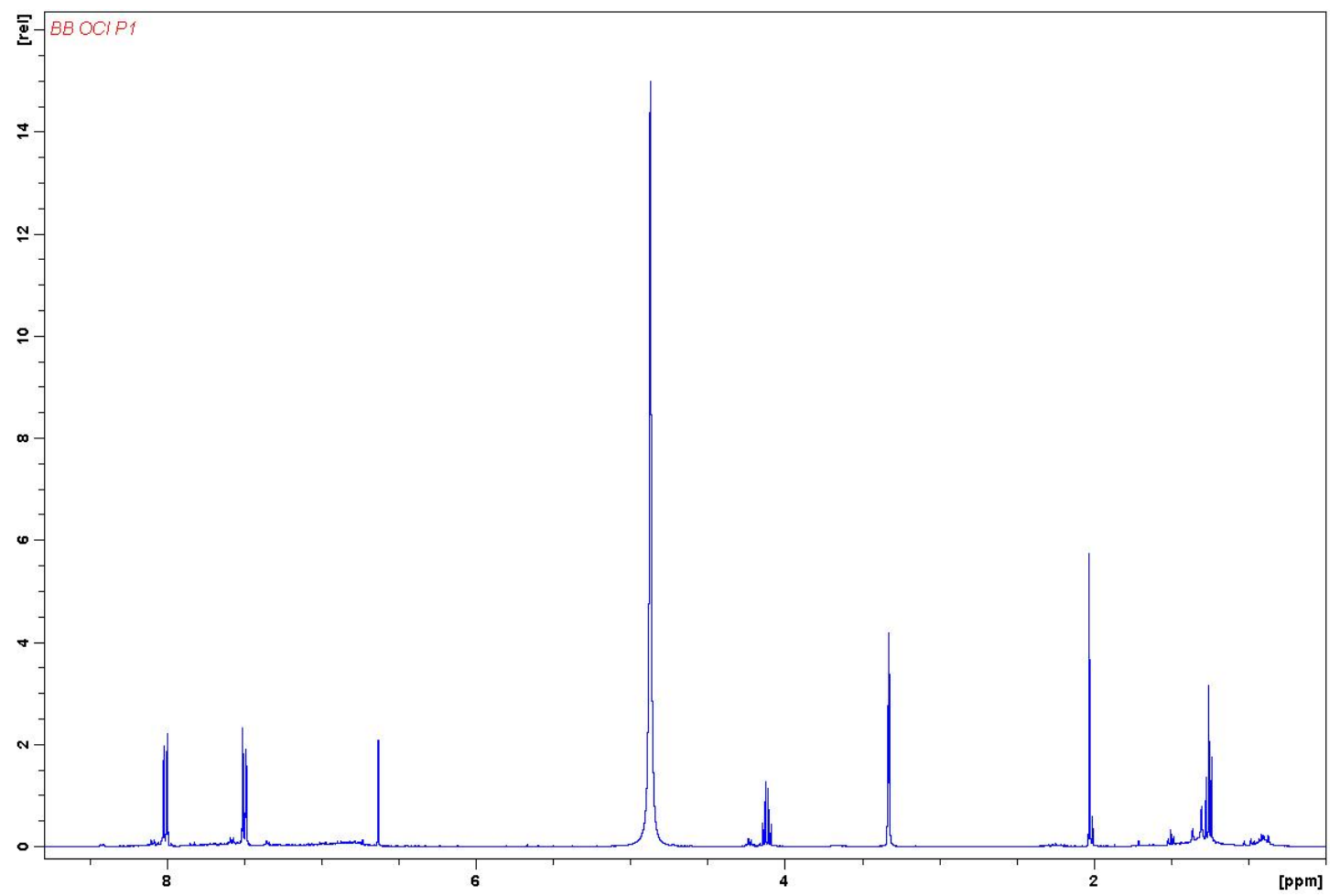

Figure S1. 1H NMR spectrum for brilliant blue-R major oxidation product $\mathrm{P}_{1}$ (4-(4-ethoxyphenylamino)-benzoic acid ) with hypochlorite. 


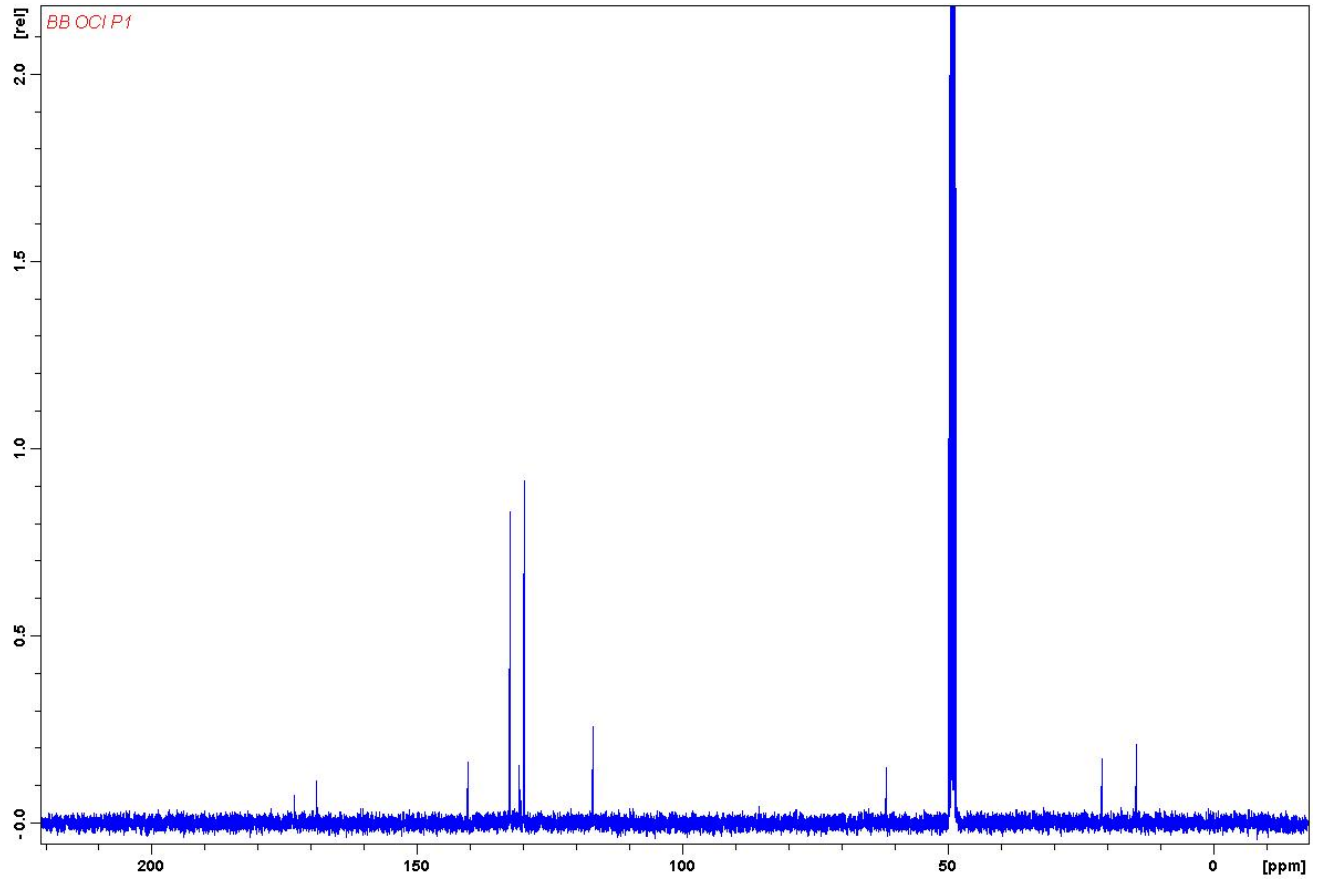

Figure S2. ${ }^{13} \mathrm{C}$ NMR spectrum for brilliant blue- $\mathrm{R}$ major oxidation product $\mathrm{P}_{1}$ (4-(4ethoxyphenylamino)-benzoic acid) with hypochlorite. 


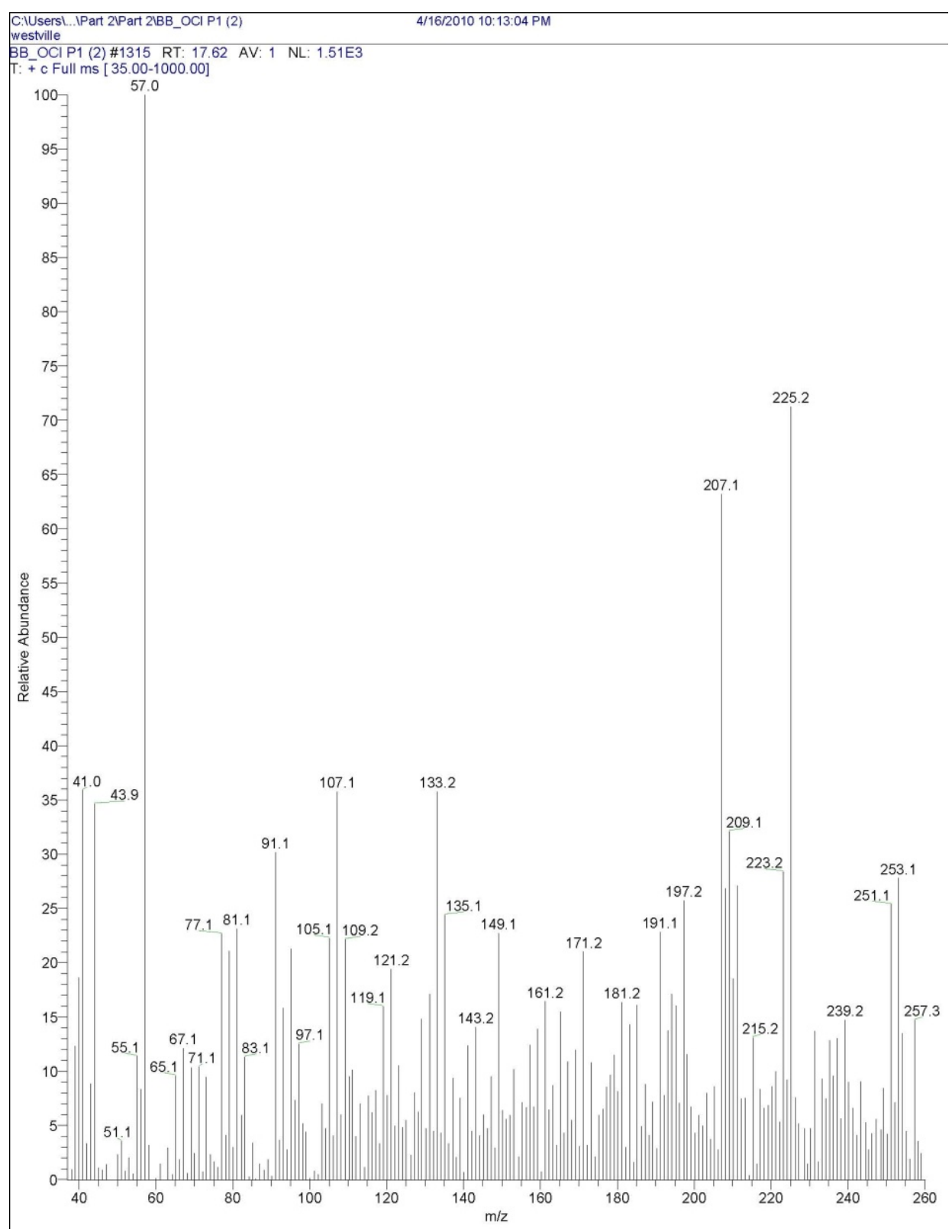

Figure S3. GC-MS spectrum for brilliant blue-R major oxidation product $\left(\mathrm{P}_{1}\right.$ (4-(4ethoxyphenylamino)-benzoic acid) with hypochlorite. 


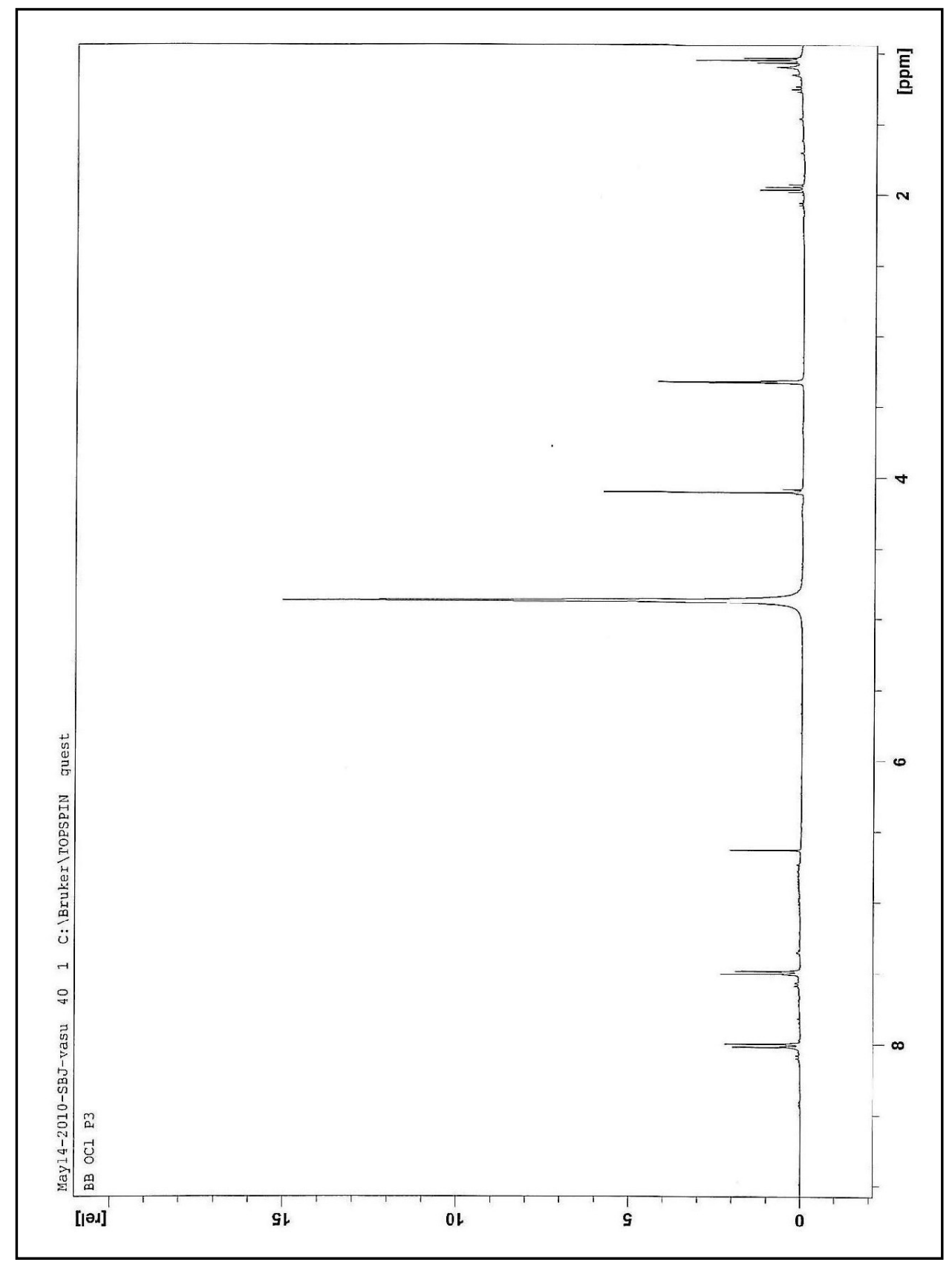

Figure S4. ${ }^{1} \mathrm{H}$ NMRspectrum for brilliant blue-R major oxidation product $\mathrm{P}_{2}$ (3- ethylaminomethylbenzenesulphonic acid) with hypochlorite. 


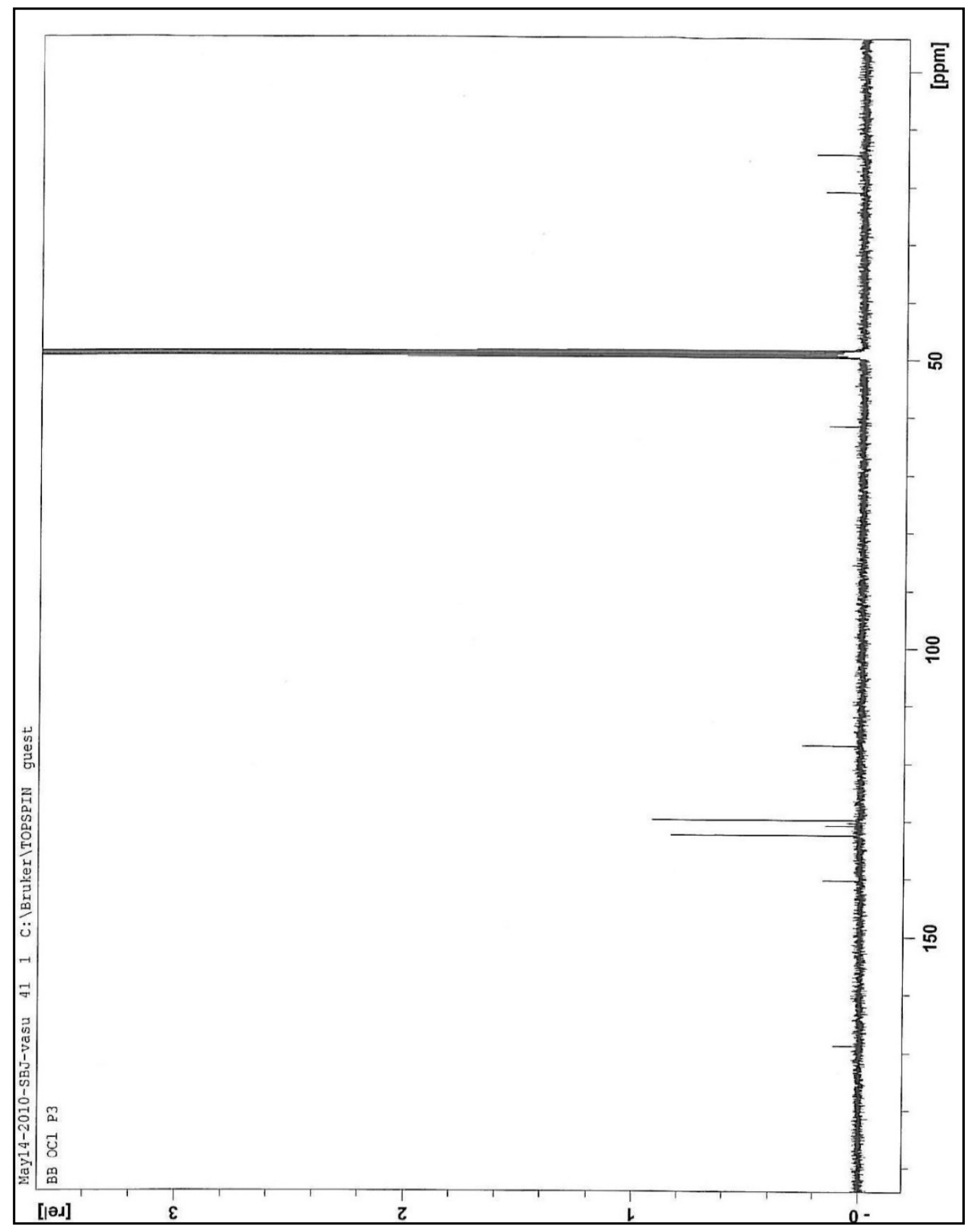

Figure S5. ${ }^{13} \mathrm{C}$ NMR spectrum for brilliant blue-R major oxidation product $\mathrm{P}_{2}$ (3- ethylamino methyl benzenesulphonic acid) with hypochlorite. 


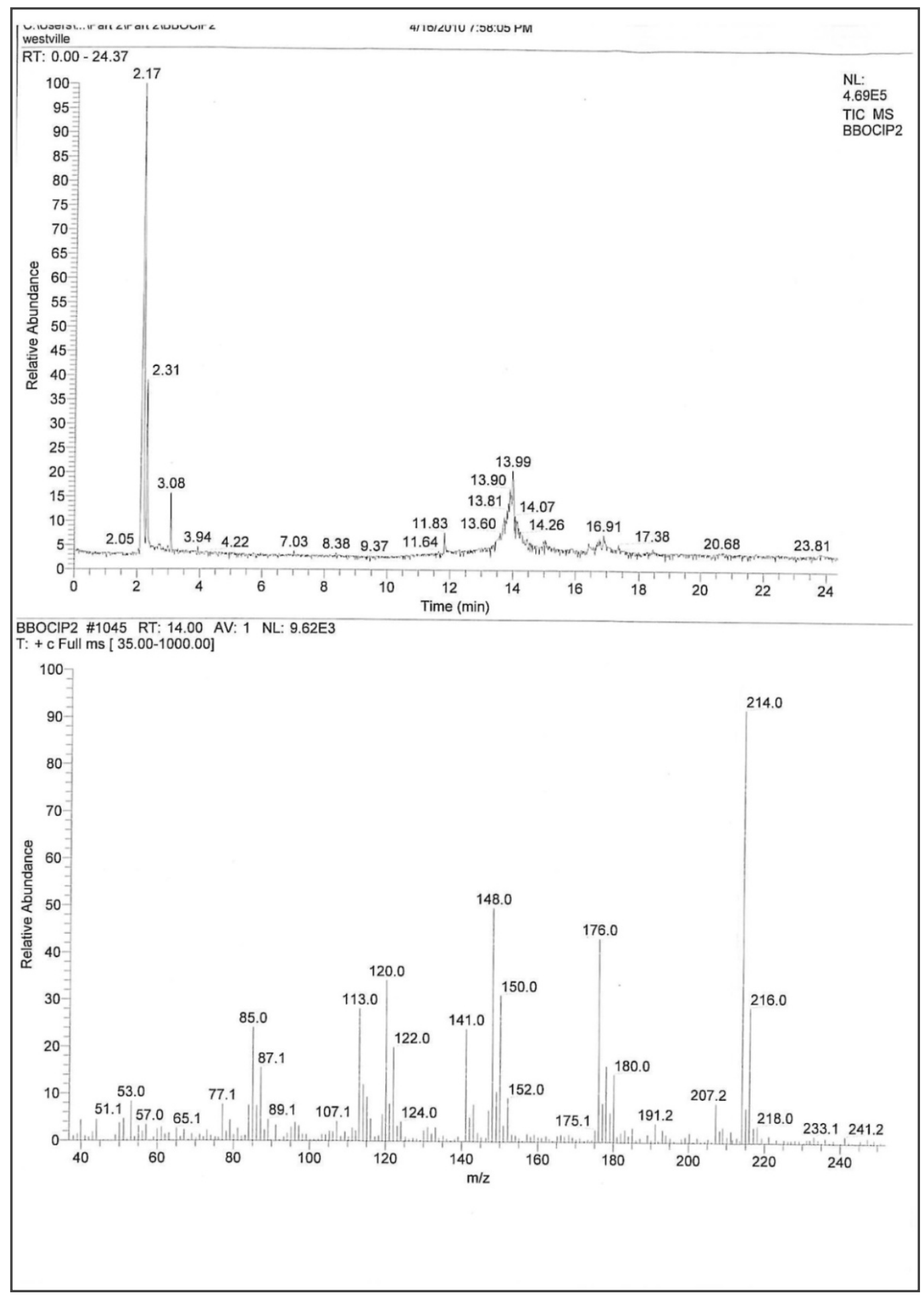

Figure S6. GC-MS spectrum for brilliant blue-R major oxidation productP $\mathrm{P}_{2}$ (3ethylaminomethylbenzenesulphonic acid) with hypochlorite. 


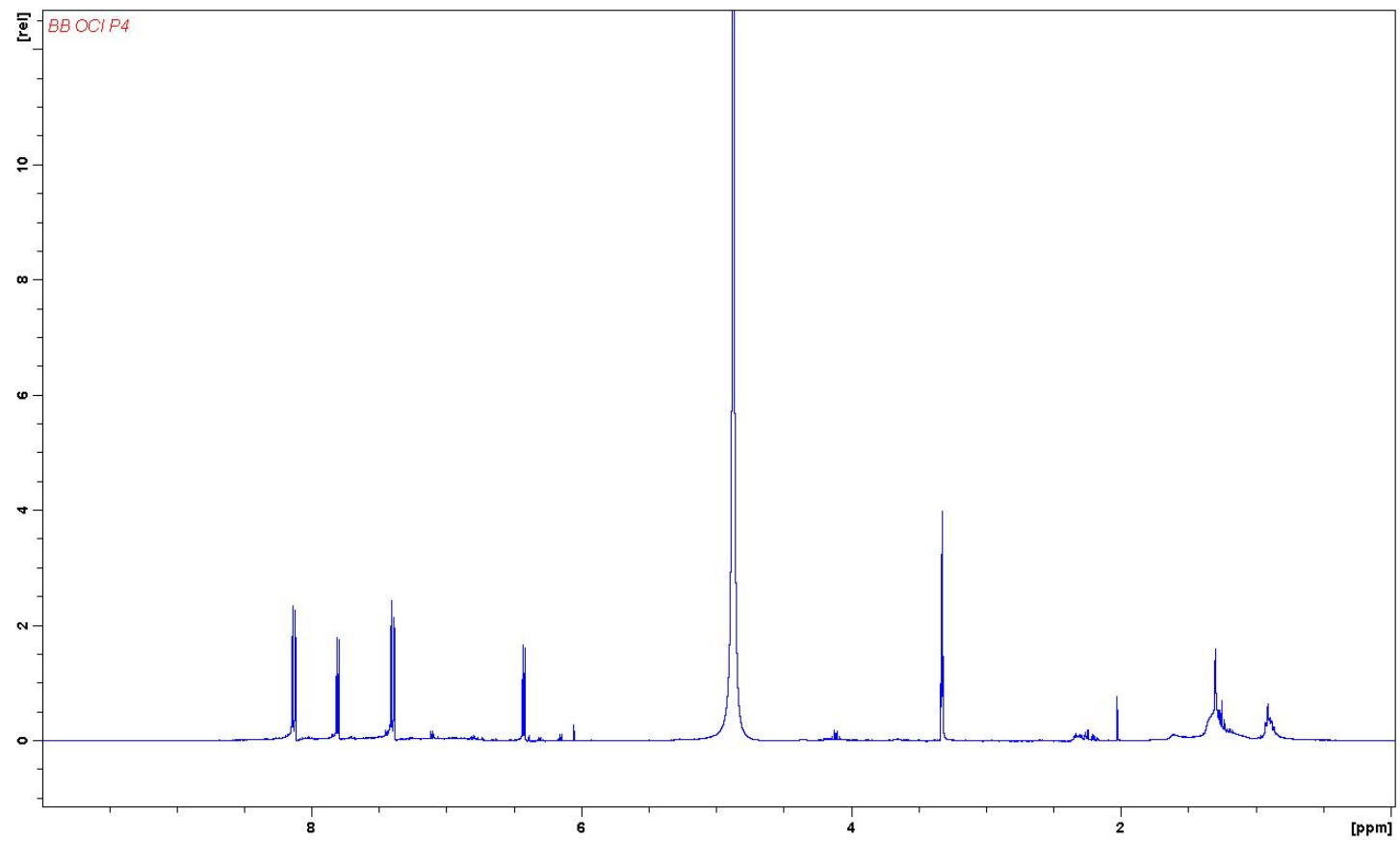

Figure S7. $\quad{ }^{1} \mathrm{H}$ NMR spectrum of brilliant blue-R major oxidation product $\mathrm{P}_{4}$ (6'chloro-5'-hydroxy-bicyclohexylidene-2,5,2'-triene-4,4'-dione) with hypochlorite.

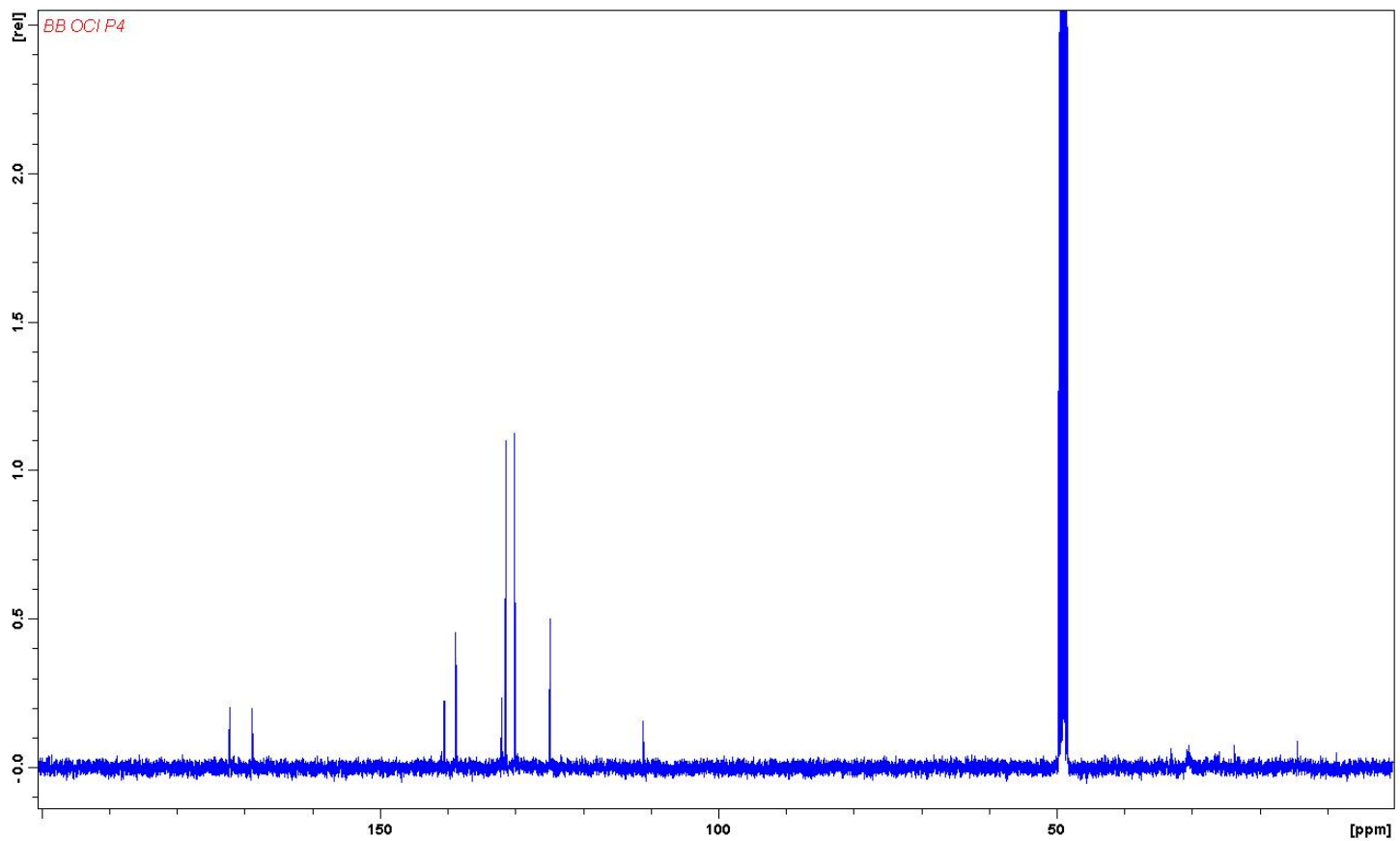

Figure $\mathrm{S} 8{ }^{13} \mathrm{C}$ NMR spectrum of brilliant blue- $\mathrm{R}$ major oxidation product $\quad \mathrm{P}_{4}\left(6^{\prime}-\right.$ chloro-5' -hydroxy-bicyclohexylidene-2,5,2'-triene-4,4'-dione) with hypochlorite. 


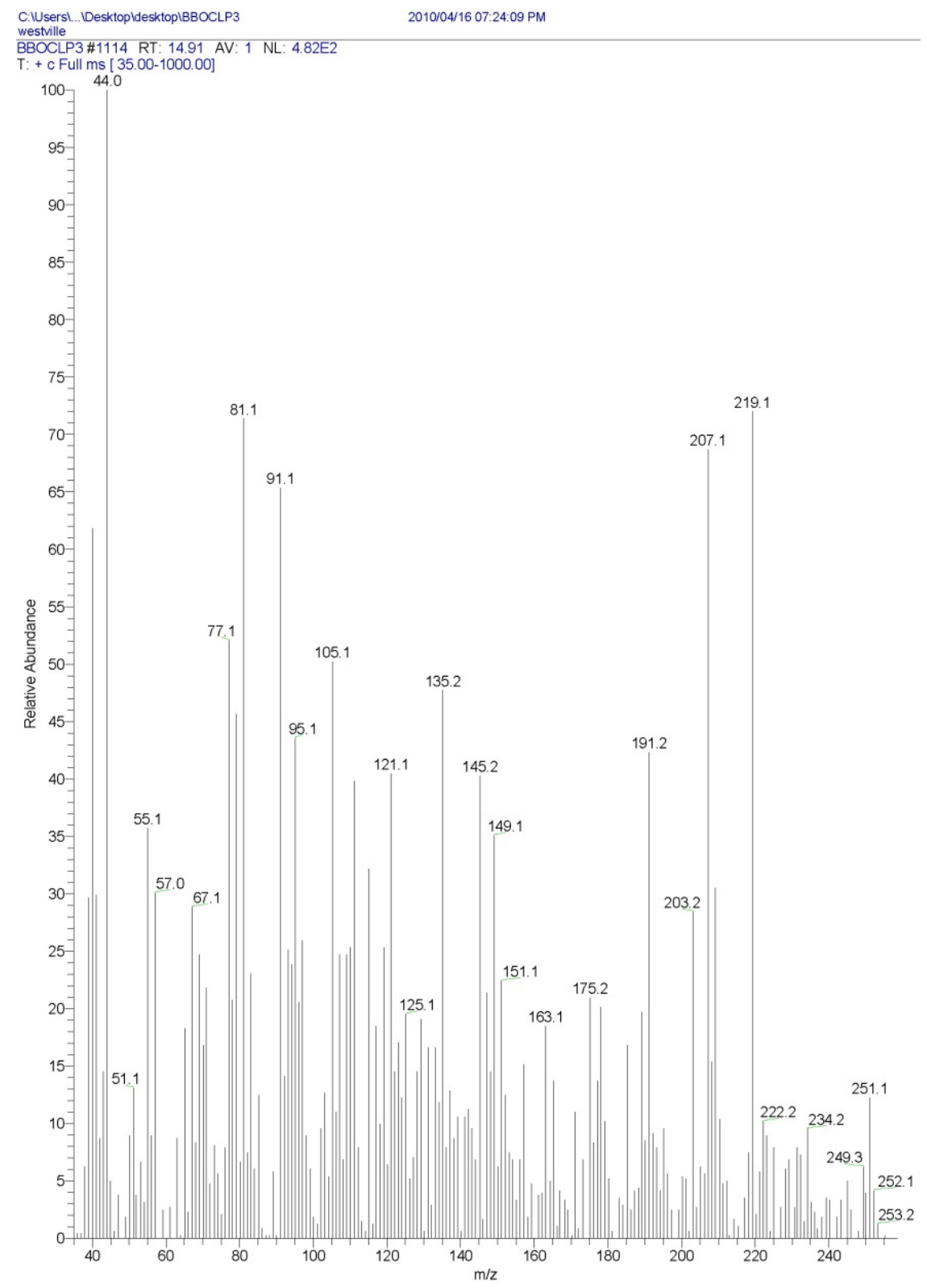

Figure S9. GC-MS spectrum of brilliant blue-R major oxidation product $\mathrm{P}_{4}$ (6' 'chloro-5' $^{\prime}$ hydroxy-bicyclohexylidene-2,5,2'-triene-4,4'-dione) with hypochlorite. 